\title{
Role and mechanism of action of LRIG1 in ovarian cancer cell line and VP16 drug-resistant cell line
}

\author{
YAQI ZHANG* ${ }^{*}$ ZHIZHEN LIU* and SHUNRUI YU \\ Department of Gynecology, Yidu Central Hospital of Weifang, Weifang, Shandong 262500, P.R. China
}

Received March 31, 2017; Accepted August 1, 2017

DOI: $10.3892 / \mathrm{ol} .2017 .6730$

\begin{abstract}
We investigated the role of leucine-rich repeats and immunoglobulin-like domains (LRIG)-1 in ovarian cancer cell line and VP16 drug-resistant cell line to explore the possible mechanism of action. Human ovarian cancer cell line SKOV3 and the VP16 drug-resistant cell line SKOV3/VP16 were used to investigate whether LRIG1 affects the sensitivity of SKOV3 to drugs. RT-qPCR was used to detect the difference in LRIG1 expression between drug-resistant and wild-type cell lines. siRNA LRIG1 was designed and transfected to silence LRIG1 to investigate the mechanism by which LRIG1 affects the sensitivity of SKOV3 to drugs. Wild-type cells were transfected with SKOV3. The cells were divided into 3 groups (VP16, NC + VP16 and siRNA LRIG1 + VP16 treatment group). VP16 ( $\mathrm{IC}_{50}$ value) was added $24 \mathrm{~h}$ after transfection. The CCK-8 method was used to detect the proliferation of each group at multiple time points $(0,24,48$ and $72 \mathrm{~h})$. A colony-forming assay was used to detect cell proliferation and flow cytometry was used to detect cell apoptosis. The expression of LRIG1 was lower in the drug resistant cell line than that of the wild-type cell line. The expression of LRIG1 significantly decreased with the increase of VP16 concentration $(\mathrm{P}<0.05)$. The apoptotic rate was decreased but there was an increase on cell clones in the siLRIG1 + VP16-treated group as compared to VP16- and NC+ VP16-treated groups $(\mathrm{P}<0.05)$. The LRIG1 gene affects the sensitivity of SKOV3 cells to drug in a dose-related manner, indicating that the reduced expression of LRIG1 can inhibit cell apoptosis.
\end{abstract}

\section{Introduction}

Ovarian cancer is a common malignant tumor of female genitalia. The incidence of ovarian cancer is ranked third among

Correspondence to: Dr Yaqi Zhang, Department of Gynecology, Yidu Central Hospital of Weifang, 4138 South Linglong Shan Road, Weifang, Shandong 262500, P.R. China

E-mail: yj39bn@163.com

*Contributed equally

Key words: ovarian, cancer, drug resistance, leucine-rich repeats and immunoglobulin-like domains 1, VP16, SKO all the malignant tumors which is lower only to that of cervical cancer and uterine cancer $(1,2)$. However, the mortality rate of ovarian epithelial cancer is the highest among all the gynecological tumors (2). With the increase use of chemotherapeutic agents, drug resistance of cancer cells poses a challenge and has attracted attention. At present, the most common type of drug resistance in ovarian cancer is the resistance to VP16. VP-16 is a cell cycle-specific antineoplastic drug that acts on the late stage or G2 phase of cell division. VP-16 can bind topoisomerase II to form a drug-enzyme-DNA stable but fragile complex, which in turn affects the function of DNA topoisomerase II. However, drug resistance is easy to develope during VP-16 treatment $(3,4)$.

Leucine-rich repeat and immunoglobulin-like domain (LRIG)-1, 2 and 3 are a class of novel tumor suppressor molecules. There is evidence to prove that LRIG-1, 2 and 3 have good prognostic value in evaluation of breast cancer (5), cervical cancer (6), head and neck cancer (7), glioma (8), prostate cancer (9), skin squamous cell carcinoma (10) and other malignant tumors.

Based on previous studies, our study aimed to further explore the roles of LRIG-1 ovarian cancer cells and drugresistant cells.

\section{Materials and methods}

Experimental materials and grouping. Experimental materials: SKOV3 and SKOV3/VP16 cell lines were purchased from the cell bank of the Chinese Academy of Medical Sciences.

Experiment grouping: i) VP16 treatment SKOV3 group; ii) $\mathrm{NC}+\mathrm{VP} 16$ treatment SKOV3 group; and iii) siRNA LRIG1 + VP16 treatment SKOV3 group.

Cell culture. Human ovarian cancer cell line SKOV3 and VP16 drug-resistant cell line SKOV3/VP16 cells were used for the experiments. The drug-resistant cells were treated with VP16 at a persistent concentration of $1 \mathrm{mg} / \mathrm{l}$.

Experimental reagents and instruments. The following were purchased: Fetal bovine serum (Gibco, Carlsbad, CA, USA); DMEM-high glucose medium (Hyclone, CA, USA); streptomycin, phosphate-buffered saline (PBS) and Cell Counting kit (CCK)-8, (Dojindo, Kumamoto, Japan), Lipofectamine $^{\mathrm{TM}} 2000$ (Invitrogen, Carlsbad, CA, USA); Annexin V/PI apoptosis kit (Liankebio, Hangzhou, China); 
crystal violet dyeing solution (home-prepared); RNA extraction reagents: TRIzol (Takara, Dalian, China); Best Mas ${ }^{\circledR}$ SYBR-Green qPCR Master Mix and diethyl pyrocarbonate (DEPC) water, both from (Sigma-Aldrich, St. Louis, MO, USA); RNasin (Promega, Madison, WI, USA); Bestar qPCR RT kit (Sigma); clean bench (Suzhfou Purification Equipment Company, Suzou, China); UV spectrophotometer (UV-1206) (Shimodzu, Kyoto, Japan); refrigerated centrifuge (SCR20B) (Hitachi, Tokyo, Japan); desktop low temperature high-speed centrifuge (Eppendorf, Berlin, Germany); horizontal electrophoresis tank (Beijing Oriental Instrument Factory, Beijing, China); gel imaging system (Bio-Rad, Richmond, CA, USA); ABI9700 PCR machine (Applied Biosystems; Thermo Fisher Scientific, Inc., Waltham, MA, USA); Stratagene Mx3000P Real Time PCR machine (Agilent, Santa Clara, CA, USA); inverted microscope (Leica, Berlin, Germany); $\mathrm{CO}_{2}$ cell incubator (Thermo, Santa Rosa, CA, USA). All the primers used in this study were designed and synthesized by Shanghai Sangon Biological Engineering Technology \& Services Co., Ltd. (Shanghai, China).

\section{mRNA expression}

RNA extraction. For RNA extraction the appropriate number of cells were collected, $1 \mathrm{ml}$ TRIzol reagent was added and the mixture was agitated at room temperature for $5 \mathrm{~min}$. Chloroform $(0.2 \mathrm{ml})$ was added, mixed for $15 \mathrm{sec}$, and left to stand for $3 \mathrm{~min}$. Centrifugation was the performed at $10,500 \mathrm{x} \mathrm{g}$ for $10 \mathrm{~min}$ at $4^{\circ} \mathrm{C}$. The supernatant was removed and transferred to a new tube. An equal volume of isopropyl alcohol was added, mixed, and left to stand for $20 \mathrm{~min}$. Centrifugation was conducted at $10,500 \mathrm{x}$ g for $10 \mathrm{~min}$ at $4^{\circ} \mathrm{C}$. The liquid was then discarded. The cells were washed with $1 \mathrm{ml} 75 \%$ alcohol followed by centrifugation at $10,500 \mathrm{x}$ g for 5 min at $4^{\circ} \mathrm{C}$, after which the liquid was discarded. RNA was air dried at room temperature, and $30 \mu 1$ of DEPC water was added to dissolve the RNA. The mixture was stored at $-80^{\circ} \mathrm{C}$.

Reverse transcription. Total RNA (1 $\mu \mathrm{l})$ was used as a template to prepare a $20 \mu \mathrm{l}$ volume reverse transcription reaction system to synthesize the first strand according to the instruction of the Bestar RT-qPCR kit. The reaction solution was prepared according to the following system: $1.0 \mu \mathrm{l}$ RNA; $1.0 \mu 1$ primer mix; $\mathrm{X} \mu 1 \mathrm{DEPC} \mathrm{H}_{2} \mathrm{O}$; total, $11 \mu 1$. Then, at $65^{\circ} \mathrm{C}$ for $5 \mathrm{~min}$, and placed on ice. The reaction solution was prepared as follows: $11 \mu \mathrm{l}$ mixture from the former step; $4.0 \mu \mathrm{l}$ of $5 \mathrm{X}$ RT buffer; $1.0 \mu 1$ of RT enzyme mix; $4.0 \mu 1$ of DEPC water; at a total volume of $20 \mu \mathrm{l}$; and $37^{\circ} \mathrm{C}$ for $60 \mathrm{~min}, 98^{\circ} \mathrm{C}$ for $10 \mathrm{~min}$.

PCR assay. The primer sequences used were: GAPDH forward, 5'-TGTTCGTCATGGGTGTGAA-3' and reverse, 5'-ATGGCATGGACTGTGGTCAT-3'; LRIG1 forward, 5'-GACCCTTTCTGACCGACAA-3' and reverse, 5'-CGCTTT CCACGGCTCTTT-3'. The reaction system was $20 \mu \mathrm{l}$ (DBI Bestar $^{\circledR}$ SYBR-Green qPCR Master Mix). The reaction system was prepared according to the following system: Bestar $^{\circledR}$ SYBR-Green qPCR Master Mix $10 \mu \mathrm{l}$; PCR forward primer $(10 \mu \mathrm{M}) 0.5 \mu \mathrm{l}$; PCR reverse primer $(10 \mu \mathrm{M})$; CDNA template $1 \mu \mathrm{l}$; $\mathrm{ddH}_{2} \mathrm{O} 8 \mu \mathrm{l}$; total $20 \mu \mathrm{l}$. The PCR reaction conditions were $94^{\circ} \mathrm{C}$ for $2 \mathrm{~min}$, followed by 40 cycles of $94^{\circ} \mathrm{C}$, $58^{\circ} \mathrm{C}$ and $72^{\circ} \mathrm{C}$ for $20 \mathrm{sec}$. For the melting curve analysis, the temperature was $62-95^{\circ} \mathrm{C}$. Each sample was repeated 3 times. Fluorescence quantitative PCR was performed with Agilent Stratagene Fluorescence Quantitative PCR Mx3000P.

siRNA sequence. The primer sequences for siRNA were: siRNA sense, 5'-GGCCUACCUUUCCUUAGAATT-3' and antisense, 5'-UUCUAAGGAAAGGUAGGCCTT-3'; NC sense, 5'-UUCUCCGAACGUGUCACGUTT-3' and antisense, 5'-ACGUGACACGUUCGGAGAATT-3'.

Data processing. Data were processed using the $2^{-\Delta \Delta \mathrm{Ct}}$ method, as follows: $\mathrm{Ct}=(\mathrm{Ct}$ of target gene $-\mathrm{Ct}$ of endogenous control); $\mathrm{Ct}=$ the mean value of ( $\mathrm{Ct}$ of target gene in experimental sample - Ct of target gene in reference sample) \pm standard deviation (if no reference sample was included, the sample with the highest $\mathrm{Ct}$ value was used as a reference). The initial amount of template was calculated as the mean value of $\left(2^{-\Delta \Delta \mathrm{C} t}\right) \pm$ standard deviation.

CCK-8 method to detect cell proliferation. Plasmids used in this study were purchased from Addgene Corporation (Cambridge, MA, USA) for the vector construction.

Experimental grouping: i) VP16 treatment SKOV3 group; ii) NC + VP16 treatment SKOV3 group; and iii) siRNA LRIG1 + VP16 treatment SKOV3 group.

Experimental method. One day before transfection, $1 \times 10^{4}$ cells were inoculated into a 96-well plate containing $100 \mu \mathrm{l}$ of complete medium and the cell density at the time of transfection was $50-70 \%$. NC and siRNA LRIG1/sh LRIG1 were added to $25 \mu \mathrm{l}$ of serum-free and antibiotic-free DMEM and mixed. Lipofectamine was added to $25 \mu \mathrm{l}$ of serum-free and antibiotic-free DMEM and gently mixed and left to stand for $5 \mathrm{~min}$ at room temperature. The diluted siRNA LRIG1 and Lipofectamine reagents were mixed and left to stand at room temperature for $20 \mathrm{~min}$, and $50 \mu \mathrm{l}$ mixture was then added to each well containing cells and $50 \mu \mathrm{l}$ medium, and the plates were then gently agitated back and forth. The cell culture plate was then transferred to a $\mathrm{CO}_{2}$ incubator for $4 \mathrm{~h}$, and the medium was replaced. The culture medium was removed, and $100 \mu \mathrm{l}$ CCK-8 solution was diluted with $1 \mathrm{ml}$ complete medium at a ratio of $1: 10$ and added at $0,24,48$ and $72 \mathrm{~h}$ after transfection, respectively, avoiding air bubbles. The culture plate was kept in the incubator for $1 \mathrm{~h}$ and the microplate reader was then used to detect the OD value at $450 \mathrm{~nm}$.

Flow cytometry to detect cell apoptosis. One day before transfection, $1 \times 10^{5}$ cells were inoculated into a 6 -well plate containing $2 \mathrm{ml}$ complete medium and the cell density at the time of transfection was $50-70 \%$. Plasmid or siRNA was added to $250 \mu \mathrm{l}$ of serum-free and antibiotic-free DMEM and mixed. Lipofectamine was added to $250 \mu 1$ of serum-free and antibiotic-free DMEM and gently mixed and left to stand for $5 \mathrm{~min}$ at room temperature. The diluted siRNA LRIG1 and Lipofectamine reagents were mixed and left to stand at room temperature for $20 \mathrm{~min}$, then $500 \mu \mathrm{l}$ mixture was added to each well containing cells and medium, and the plates were then gently agitated back and forth. The cell culture plate was transferred to a $\mathrm{CO}_{2}$ incubator for $4 \mathrm{~h}$ and the medium was then 
A

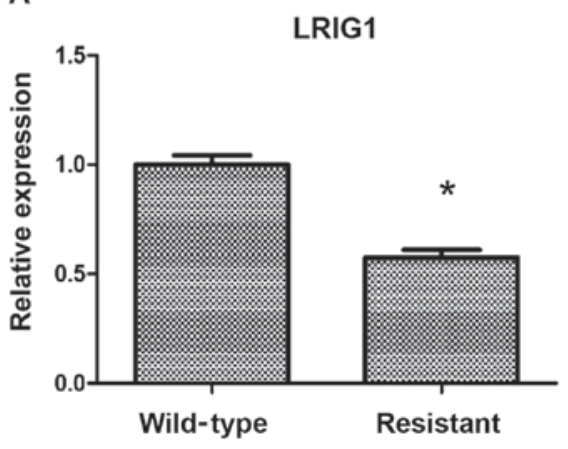

B

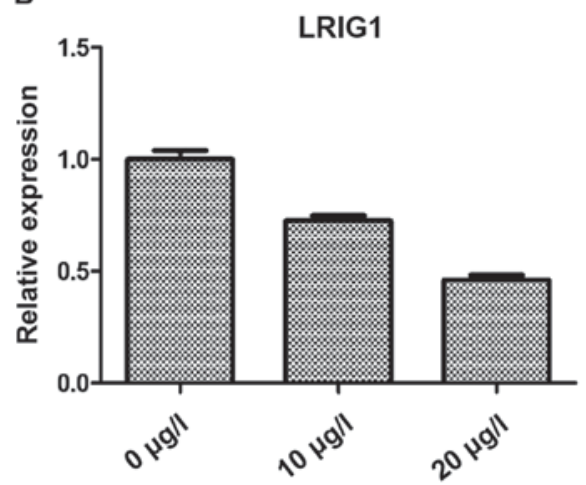

Figure 1. Expression of LRIG1 detected by RT-qPCR, (A) Compared with wild-type cells, LRIG1 expression in drug-resistant cells was significantly reduced $(\mathrm{P}<0.05)$. (B) The expression of LRIG1 was decreased significantly with the increase of VP16 concentration $\left({ }^{*} \mathrm{P}<0.05\right)$. LRIG1, leucine-rich repeats and immunoglobulin-like domains.

replaced with complete medium. The cells were collected at $5 \mathrm{~h}$ after transfection for subsequent detection. We diluted the $5 \mathrm{X}$ to $1 \mathrm{X}$ binding buffer with $\mathrm{ddH}_{2} \mathrm{O}$ and $5 \mu \mathrm{l}$ Annexin $\mathrm{V}$ and $10 \mu \mathrm{PI}$, and $0.5 \mathrm{ml} 1 \mathrm{X}$ binding buffer were mixed to prepare Annexin V/PI staining solution. The medium in the culture plate was aspirated and the cells were rinsed with $2 \mathrm{ml}$ PBS per well. PBS was then removed and $0.5 \mathrm{ml} 0.25 \%$ trypsin was added into each well, the digestion was monitored under a microscope, the trypsin was removed when cytoplasm was retracted and the cells were no longer attached to each other. Then, $2 \mathrm{ml}$ PBS was added to produce a single cell suspension and the cell suspension was transferred to a flow tube, followed by centrifugation for $5 \mathrm{~min}$ at $850 \mathrm{x} \mathrm{g}$, discarding the supernatant. Annexin V/PI staining solution $(200 \mu \mathrm{l})$ was added to resuspend the cells. The cells were incubated in the dark for 15 min and then detected.

Colony formation assay. To determine colony formation the cells were divided as follows: i) VP16 treatment SKOV3 group ii) NC + VP16 treatment SKOV3 group and iii) siRNA LRIG1 + VP16-treated SKOV3 cells were divided into groups.

Experimental method. The cells were initially collected during the exponential growth period using conventional digestion and subculture methods to prepare cell suspension. Cell suspension was mixed by pipetting to separate the cells from each other. The single cell percentage was $>95 \%$. According to the cell proliferation ability, the cell suspension was diluted. Generally, $5 \mathrm{ml}$ of cell suspension containing
Table I. Inhibition rates of cell growth under different concentrations of VP16.

\begin{tabular}{lclc}
\hline Concentrations & $\begin{array}{c}\text { Mean OD } \\
\text { value }\end{array}$ & $\begin{array}{c}\text { Mean apoptosis } \\
\text { rate }\end{array}$ & $\begin{array}{c}\text { Inhibition } \\
\text { rate }\end{array}$ \\
\hline & & & \\
0 & 0.586667 & 0.467 & 0.000000 \\
5 & 0.546333 & 0.426667 & 0.086367 \\
10 & 0.460333 & 0.340667 & 0.270521 \\
20 & 0.418333 & 0.298667 & 0.360457 \\
40 & 0.348667 & 0.229 & 0.509636 \\
80 & 0.212667 & 0.093 & 0.800857 \\
\hline
\end{tabular}

$\mathrm{IC}_{50}=30.623 \mu \mathrm{g} / \mathrm{l}$.

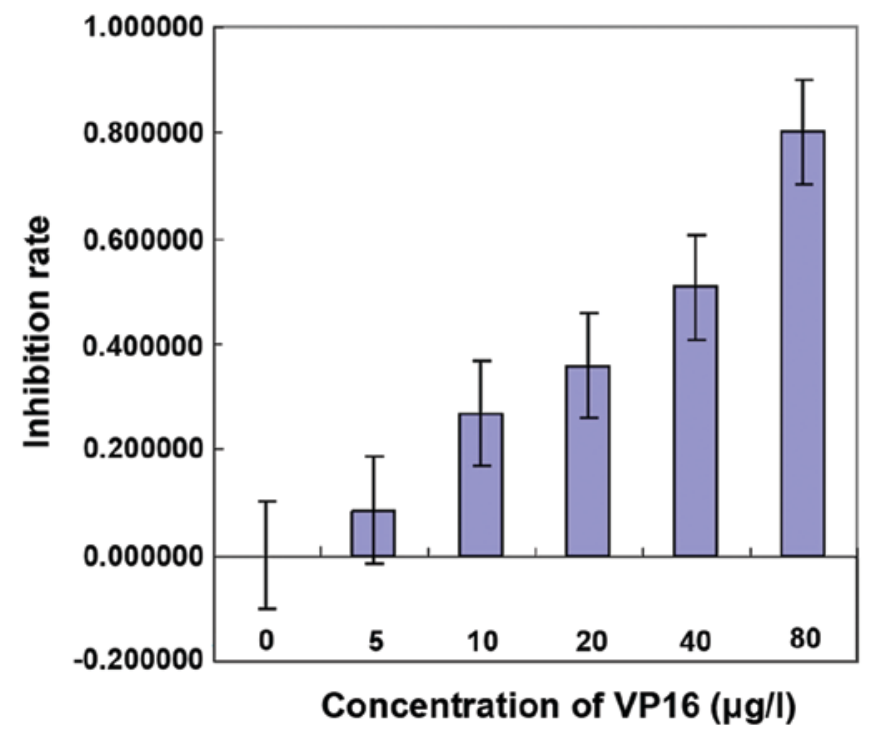

Figure 2. CCK-8 to detect tumor cell inhibition rates at different concentrations of VP16.

200 cells was inoculated into a culture dish (diameter $60 \mathrm{~mm}$ ) and the dishes were gently shaken in a cross direction to disperse the cells uniformly. The culture dish was incubated for 2 to 3 weeks $\left(37^{\circ} \mathrm{C}, 5 \% \mathrm{CO}_{2}\right)$ and fresh culture medium was used to replace the old medium according to the changes of $\mathrm{pH}$ value. When the visible clones appeared in the culture dish, the culture was terminated and the culture medium was discarded. The PBS solution was used to carefully wash the cells twice and the cells were then air-dried. The cells were fixed with methanol for $15 \mathrm{~min}$, and air-dried after discarding the methanol. Then the cells were stained with crystal violet for $10 \mathrm{~min}$, followed by washing with water. Finally, the cells were air-dried.

\section{Results}

Detection of LRIG1 expression in ovarian cancer cell lines and VP16 drug-resistant cell lines. The differences in LRIG1 expression between resistant and wild-type cells were as 


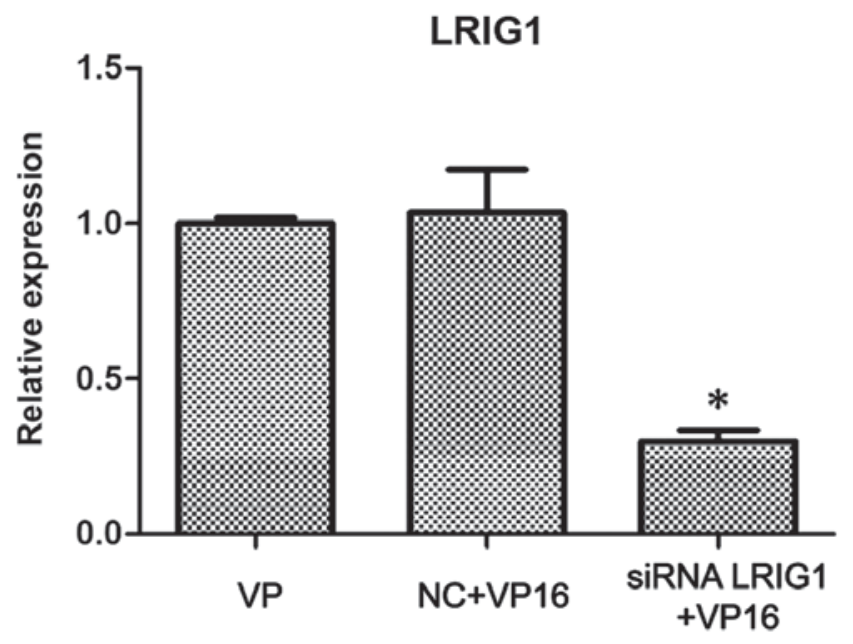

Figure 3. The expression levels of LRIG1 in SKOV3 cells after siLRIG1 transfection. Western blot analysis showed that the expression of LRIG1 protein in the siRNA LRIG1 + VP16-treated group was significantly lower than that in the VP and the NC+VP16-treated group ( $\mathrm{P}<0.05)$. LRIG, leucine-rich repeats and immunoglobulin like domains.

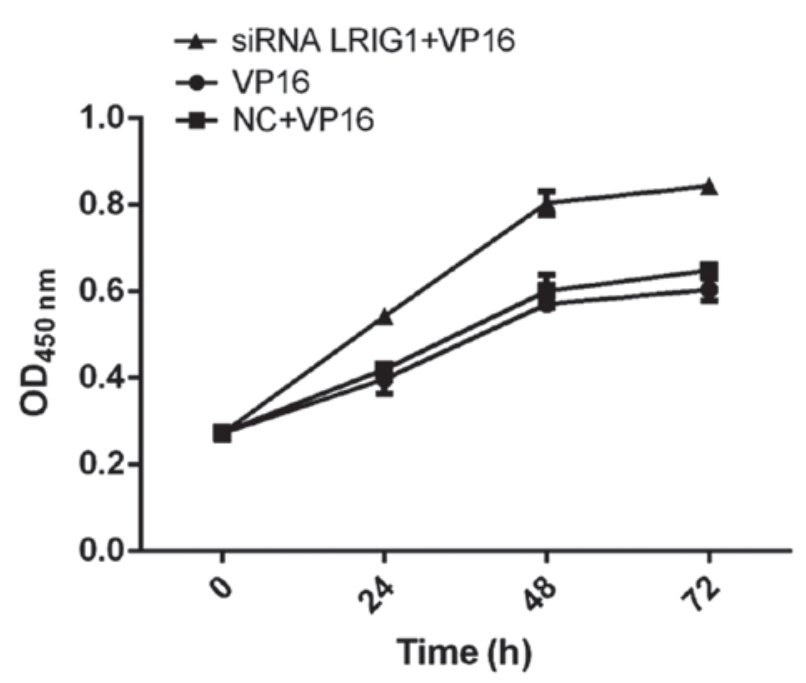

Figure 4. Cell viability detected by CCK- 8 method. The cell viability of siRNA LRIG1 + VP16 treatment group was significantly higher than that of VP16 and NC + VP16, suggesting that silencing LRIG1 can promote cell viability. LRIG1, leucine-rich repeats and immunoglobulin-like domains; CCK, cell counting kit.

follows: Compared with the wild-type cells, the expression level of LRIG1 in drug resistant cells was significantly decreased $(\mathrm{P}<0.05)$ (Fig. 1A). Based on this result, three VP16 concentrations were used to treat SKOV3 cells for $48 \mathrm{~h}$, and RT-qPCR was then used to detect the expression of LRIG1. We found that the expression of LRIG1 was significantly decreased with the increase of VP16 concentration $(\mathrm{P}<0.05)$ (Fig. 1B).

Effect of VP16 on the IC ${ }_{50}$ of SKOV3. CCK-8 was used to detect the effect of VP16 on the $\mathrm{IC}_{50}$ of SKOV3. Different concentrations of VP16 $(0,5,10,20,40$ and $80 \mu \mathrm{g} / \mathrm{l})$ were used to treat the cells. The results showed that the inhibition rate of tumor cell growth was related to the concentration of VP16. The higher VP16 concentration was followed by the stronger ability of
VP16 to inhibit the growth of tumor cells, in a dose-dependent manner. The results showed that $\mathrm{IC}_{50}=30,623 \mu \mathrm{g} / \mathrm{l}$ (Fig. 2, Table I).

Silencing of LRIG1 in SKOV3 cells. The siRNA LRIG1 was designed and used to transfect wild-type SKOV3. After $24 \mathrm{~h}$, VP16 $\left(\mathrm{IC}_{50}\right)$ was added. After 48 -h treatment, the cells were divided into the VP16, NC + VP16 and siRNA LRIG1 + VP16 treatment group. The western blot analysis showed that the expression of LRIG1 protein in the siRNA LRIG1 + VP16 treated group was significantly lower than that in the VP16 and the NC + VP16-treated group $(\mathrm{P}<0.05)$ (Fig. 3).

Cell viability detected by $C C K-8$ method. The cell viability of siRNA LRIG1 + VP16 treatment group was significantly higher than that of VP16 and NC + VP16 treatment group, suggesting that silencing LRIG1 can promote cell viability (Fig. 4).

Cell apoptosis detection. Compared with VP16 and NC + VP16 treatment group, the apoptotic rate was significantly increased in siLRIG1 + VP16 treatment group $(\mathrm{P}<0.05)$, indicating that silencing LRIG1 can promote cell apoptosis (Fig. 5).

Cell proliferation detected by colony formation assay. The cells in VP16, NC+VP16 and siRNA LRIG1 + VP16 treatment group were subjected to a colony formation assay. Compared with VP16 and NC+VP16 treatment group, the number of colonies formed by cells in siRNA LRIG1 + VP16 treatment group was increased significantly $(\mathrm{P}<0.05)$ (Fig. 6).

\section{Discussion}

Since its discovery 10 years ago, LRIG1 was assumed to be a tumor suppressor gene (11-13). A series of experimental and clinical data have supported this hypothesis. Studies have found that LRIG1 can inhibit the normal proliferation and differentiation of cells. LRIG1 plays an important regulatory role in prostate cancer cells, mouse fibroblast keratinocytes, bladder cancer cells, breast cancer cells, astrocytomas, glioblastoma cells (14-20) and other cell lines.

The mechanism of action of VP16, a chemotherapeutic agent, exerts a cell cycle-specific antitumor effect by interfering with DNA topoisomerase II. However, drug resistance develops after long-term use of VP16, especially in lung adenocarcinoma, ovarian cancer and endometrial cancer and other malignant tumors. The specific mechanism of this drugresistance remains unkown. For their drug-resistant property, VP16 cells are widely used in basic research. Our study found that LRIG1 expression in drug-resistant cells was lower than that in wild-type cells and the expression of LRIG1 was significantly decreased with the increase of VP16 concentration $(\mathrm{P}<0.05)$. After LRIG1 silencing by siRNA interference, less apoptotic cells and more colonies were found in siLRIG1 + VP16 treatment group compared with VP16 and $\mathrm{NC}+\mathrm{VP} 16$ treatment group $(\mathrm{P}<0.05)$. This result indicates that LRIG1 can promote the proliferation of ovarian cancer cells and after silencing, the cell proliferation ability is weakened and the apoptosis is increased. This conclusion is consistent with previous studies $(21,22)$, suggesting that we can promote apoptosis of tumor cells by reducing the expression of LRIG1 
NC+VP16

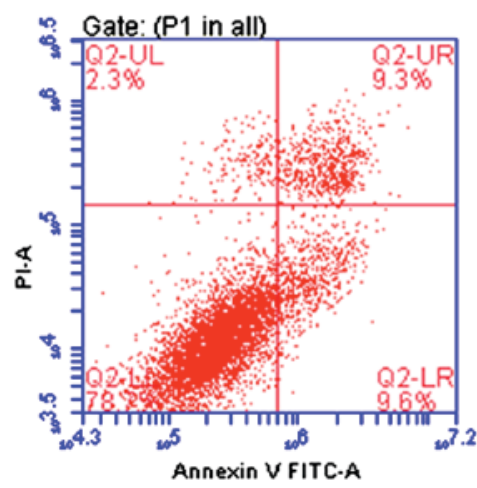

VP16

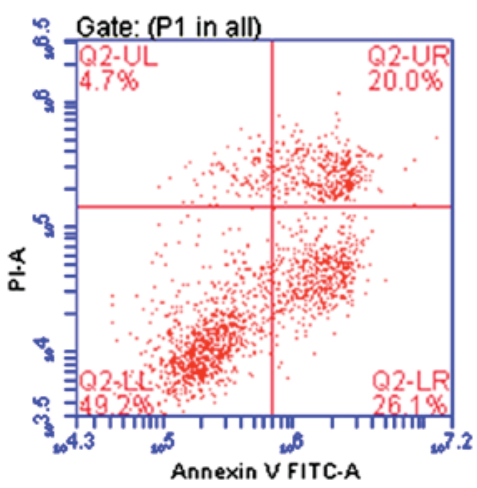

siRNA LRIG1

+VP16

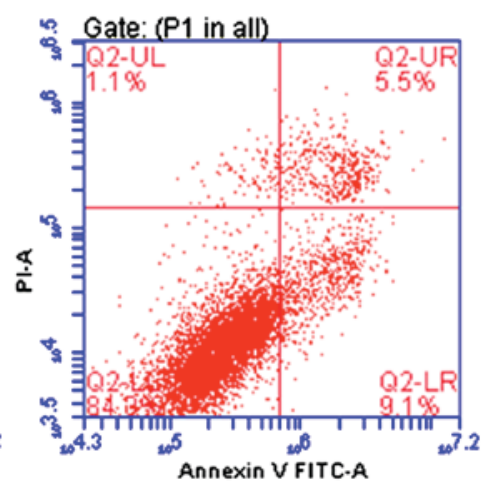

Figure 5. Cell apoptosis detected by flow cytometry. Compared with VP16 and NC + VP16 treatment group, the proportion of apoptotic cells in siLRIG1 + VP16 treatment group was significantly decreased $(\mathrm{P}<0.05)$.

A
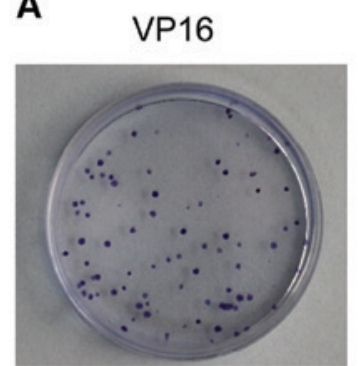

$\mathrm{NC}+\mathrm{VP} 16$

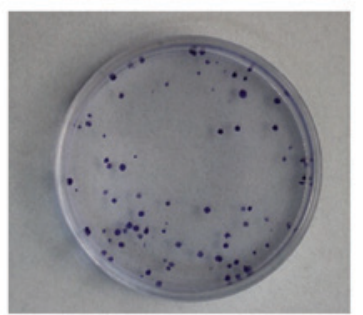

SiRNA LRIG1

+VP16

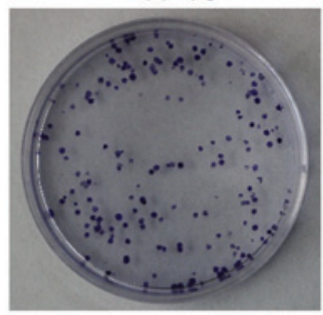

B

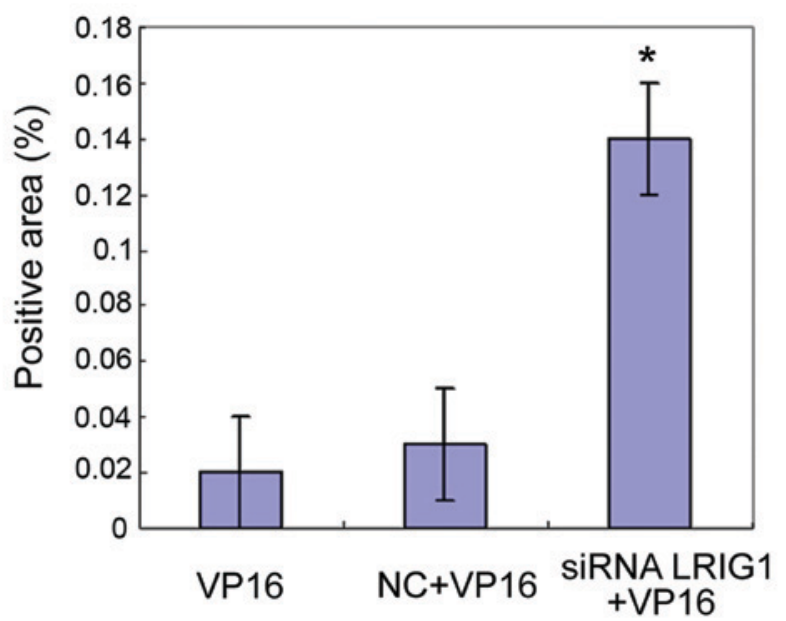

Figure 6. Cell proliferation detected by colony formation assay. (A) Reprentative results of the colony formation assay of cells in VP16, NC + VP16 treatment group and siRNA LRIG1 + VP16 treatment group. (B) Compared with VP16 and NC + VP16 treatment group, the number of colonies formed by cells in the siRNA LRIG1 + VP16 treatment group was increased significantly $\left({ }^{*} \mathrm{P}<0.05\right)$.

protein in the treatment of ovarian cancer, to improve the sensitivity of cancer cells to radiotherapy and chemotherapy.

At the molecular level, LRIG1 negatively regulates the growth factor signaling mediated by the oncogenic receptor tyrosine kinase. LRIG1 can induce the ubiquitination of epidermal growth factor receptor (EGFR) family members including EGFR, ErbB2 (also known as HER2), ErbB3 and $4(14,15)$, thereby destroying the MET receptor (18), thereby acting on the RET receptor and inhibiting the phosphorylation of RET and downstream factors $(23,24)$. In general, LRIG1 can inhibit cell proliferation through a variety of regulatory pathways. Previous findings have shown that LRIG1 expression is associated with sex hormone expression (18). The LRIGl gene can be expressed in most normal human tissues and cells (20-23). In addition to the above-metioned regulatory pathway, LRIG2 can induce transcription of the LRIG1 gene though the growth factor (23) or steroids (1-11). In ErbB2-positive tumor cell lines, overexpression of ErbB2 downregulates the expression of estrogen receptors, thereby inhibiting estrogen-induced LRIG1 transcription (1-19). The natural compound, gambogic acid, can upregulate the expression of 
LRIG1 in glioma cells by activating AMP kinase, thereby inhibiting the proliferation of these cells (24). Therefore, from results of this study, it can be concluded that LRIGI gene affects the sensitivity of SKOV3 cells to drugs in a dose-dependent manner, indicating that LRIG1 silencing can inhibit cell apoptosis. Increasing the expression level of LRIG1 in ovarian cancer cells can improve the chemoradiotherapy sensitivity of ovarian cancer cells.

In conclusion, LRIG1 gene affects the sensitivity of SKOV3 cells to chemotherapeutic drugs in a dose-dependent manner, indicating that LRIG1 silencing can inhibit cell apoptosis.

\section{References}

1. Krig SR, Frietze S, Simion C, Miller JK, Fry WH, Rafidi H, Kotelawala L, Qi L, Griffith OL, Gray JW, et al: Lrig1 is an estrogen-regulated growth suppressor and correlates with longer relapse-free survival in ER $\alpha$-positive breast cancer. Mol Cancer Res 9: 1406-1417, 2011.

2. Thompson PA, Ljuslinder I, Tsavachidis S, Brewster A, Sahin A, Hedman H, Henriksson R, Bondy ML and Melin BS: Loss of LRIG1 locus increases risk of early and late relapse of stage I/II breast cancer. Cancer Res 74: 2928-2935, 2014.

3. Lindström AK, Ekman K, Stendahl U, Tot T, Henriksson R, Hedman $\mathrm{H}$ and Hellberg D: LRIG1 and squamous epithelial uterine cervical cancer: Correlation to prognosis, other tumor markers, sex steroid hormones and smoking. Int J Gynecol Cancer 18: 312-317, 2008

4. Hedman H, Lindström AK, Tot T, Stendahl U, Henriksson R and Hellberg D: LRIG2 in contrast to LRIG1 predicts poor survival in early-stage squamous cell carcinoma of the uterine cervix. Acta Oncol 49: 812-815, 2010.

5. Muller S, Lindquist D, Kanter L, Flores-Staino C, Henriksson R, Hedman $\mathrm{H}$ and Andersson S: Expression of LRIG1 and LRIG3 correlates with human papillomavirus status and patient survival in cervical adenocarcinoma. Int J Oncol 42: 247-252, 2013.

6. Sheu JJ, Lee CH, Ko JY, Tsao GS, Wu CC, Fang CY, Tsai FJ, Hua CH, Chen CL and Chen JY: Chromosome 3p12.3-p14.2 and $3 q 26.2-q 26.32$ are genomic markers for prognosis of advanced nasopharyngeal carcinoma. Cancer Epidemiol Biomarkers Prev 18: 2709-2716, 2009.

7. Sheu JJ, Lee CC, Hua CH, Li CI, Lai MT, Lee SC, Cheng J, Chen CM, Chan C, Chao SC, et al: LRIG1 modulates aggressiveness of head and neck cancers by regulating EGFR-MAPK-SPHK1 signaling and extracellular matrix remodeling. Oncogene 33: 1375-1384, 2014.

8. Lindquist D, Näsman A, Tarján M, Henriksson R, Tot T, Dalianis T and Hedman H: Expression of LRIG1 is associated with good prognosis and human papillomavirus status in oropharyngeal cancer. Br J Cancer 110: 1793-1800, 2014.

9. Guo D, Nilsson J, Haapasalo H, Raheem O, Bergenheim T, Hedman $\mathrm{H}$ and Henriksson R: Perinuclear leucine-rich repeats and immunoglobulin-like domain proteins (LRIG1-3) as prognostic indicators in astrocytic tumors. Acta Neuropathol 111: 238-246, 2006.
10. Holmlund C, Haapasalo H, Yi W, Raheem O, Brännström T, Bragge H, Henriksson R and Hedman H: Cytoplasmic LRIG2 expression is associated with poor oligodendroglioma patient survival. Neuropathology 29: 242-247, 2009.

11. Thomasson M, Wang B, Hammarsten P, Dahlman A, Persson JL, Josefsson A, Stattin P, Granfors T, Egevad L, Henriksson R, et al: LRIG1 and the liar paradox in prostate cancer: A study of the expression and clinical significance of LRIG1 in prostate cancer. Int J Cancer 128: 2843-2852, 2011.

12. Tanemura A, Nagasawa T, Inui S and Itami S: LRIG-1 provides a novel prognostic predictor in squamous cell carcinoma of the skin: Immunohistochemical analysis for 38 cases. Dermatol Surg 31: 423-430, 2005

13. Hedman H, Nilsson J, Guo D and Henriksson R: Is LRIG1 a tumour suppressor gene at chromosome 3p14.3? Acta Oncol 41: 352-354, 2002.

14. Gur G, Rubin C, Katz M, Amit I, Citri A, Nilsson J, Amariglio N, Henriksson R, Rechavi G, Hedman H, et al: LRIG1 restricts growth factor signaling by enhancing receptor ubiquitylation and degradation. EMBO J 23: 3270-3281, 2004.

15. Laederich MB, Funes-Duran M, Yen L, Ingalla E, Wu X, Carraway KL III and Sweeney C: The leucine-rich repeat protein LRIG1 is a negative regulator of ErbB family receptor tyrosine kinases. J Biol Chem 279: 47050-47056, 2004.

16. Jensen KB and Watt FM: Single-cell expression profiling of human epidermal stem and transit-amplifying cells: Lrig1 is a regulator of stem cell quiescence. Proc Natl Acad Sci USA 103: 11958-11963, 2006.

17. Yang WM, Yan ZJ, Ye ZQ and Guo DS: LRIG1, a candidate tumour-suppressor gene in human bladder cancer cell line BIU87. BJU Int 98: 898-902, 2006.

18. Shattuck DL, Miller JK, Laederich M, Funes M, Petersen H, Carraway KL III and Sweeney C: LRIG1 is a novel negative regulator of the Met receptor and opposes Met and Her2 synergy. Mol Cell Biol 27: 1934-1946, 2007.

19. Miller JK, Shattuck DL, Ingalla EQ, Yen L, Borowsky AD, Young LJ, Cardiff RD, Carraway KL III and Sweeney C: Suppression of the negative regulator LRIG1 contributes to ErbB2 overexpression in breast cancer. Cancer Res 68: 8286-8294, 2008.

20. Nilsson J, Vallbo C, Guo D, Golovleva I, Hallberg B, Henriksson R and Hedman $\mathrm{H}$ : Cloning, characterization, and expression of human LIG1. Biochem Biophys Res Commun 284: 1155-1161, 2001.

21. Holmlund C, Nilsson J, Guo D, Starefeldt A, Golovleva I, Henriksson R and Hedman $\mathrm{H}$ : Characterization and tissue-specific expression of human LRIG2. Gene 332: 35-43, 2004.

22. Guo D, Holmlund C, Henriksson R and Hedman H: The LRIG gene family has three vertebrate paralogs widely expressed in human and mouse tissues and a homolog in Ascidiacea. Genomics 84: 157-165, 2004.

23. Nilsson J, Starefeldt A, Henriksson R and Hedman H: LRIG1 protein in human cells and tissues. Cell Tissue Res 312: 65-71, 2003.

24. Ledda F, Bieraugel O, Fard SS, Vilar M and Paratcha G: Lrig1 is an endogenous inhibitor of Ret receptor tyrosine kinase activation, downstream signaling, and biological responses to GDNF. J Neurosci 28: 39-49, 2008. 